\title{
A STRUCTURED PROCESS FOR TRANSFERRING ACADEMIC RESEARCH INTO INNOVATION PROJECTS - PIMES CASE STUDY
}

\author{
Carsten Wolff ${ }^{1)}$, Burkhard Igel ${ }^{2)}$, Uwe Lauschner ${ }^{3)}$ \\ ${ }^{1)}$ Dortmund University of Applied Sciences and Arts, Emil-Figge-Str. 42, 44227 Dortmund, Germany, \\ carsten.wolff@fh-dortmund.de, www.pimes.de \\ ${ }^{2)}$ Dortmund University of Applied Sciences and Arts, Sonnenstr. 96, 44139 Dortmund, Germany \\ ${ }^{3)}$ Dortmund University of Applied Sciences and Arts, Otto-Hahn-Str. 23, 44227 Dortmund, Germany \\ uwe.lauschner@fh-dortmund.de,www.pimes.de
}

\begin{abstract}
Academic research is promoting the free mind. The intention is to discover new findings in early phases of the innovation process. The researchers consider their creativity to be dependent on freedom and openness. Nevertheless, today's research institutions are large and many of them conduct a business projects requiring a constant flow of projects and results. The challenge is to use professional innovation processes without destroying creativity and freedom. Ideas need to have a chance to result into a research project and scientists need to be protected from too much administration. Innovation processes for academic research need to be lean, simple, efficient and effective. This paper presents processes and tools for the early phase of transferring an innovative idea into a funding project. They are based on an IT platform which allows web based access from any place at any time. Results from the application in a research group are evaluated. Copyright $\mathbb{C}$ ( Research Institute for Intelligent Computer Systems, 2014. All rights reserved.
\end{abstract}

Keywords: R\&D Projects, Innovation Management, Academic Research, Scorecard, Innovation Funnel, Trend Spotting, IT tools for Innovation Processes.

\section{INTRODUCTION}

Academic research is expected to create a constant flow of innovations and research results to serve the public needs of the financing society. There is lots of debate about how much bureaucratization and formalism this expectation justifies and how much academic freedom is still possible $[2,8,10]$.

Nevertheless, academic researchers have to cope with the situation. There is a demand for a professional management system for academic research. This system has to be lean and efficient to prevent researchers from being buried in administration work, but it has to be effective in yielding a sufficient flow of innovations and results, too. Today, academic research institutions are evaluated according to these results and their funding is strongly dependent on this.

Success needs to be measured and reported by using key performance indicators. In a joint strategy development and according to agreements with funding authorities and the university board, quantitative targets are set and need to be achieved. In addition, research institutions and universities have an intrinsic motivation to be excellent in research because this important for their reputation.

These constraints are the reason to strive for a professionalization of research management in academia [12]. An important step in academic research is the acquisition of funding for a research project. This specific "result" is to some extent one of the "products" of the research industry. Therefore, the focus of this contribution is the process needed to come from a promising idea to a funded project.

The following chapters are based on a previous publication [15] and describe a structured process for getting from a new idea to a funding for a research project. First, the characteristics and main drivers for bringing an idea to the stage of a funding decision are described. Based on these drivers, a process and tools for managing the development of a successful funding proposal are described. The tools are implemented within an IT collaboration suite.

The research centre PIMES [20] of the Dortmund University of Applied Sciences and Arts is using this process and the respective tools. It serves as a case study. The findings from the evaluation of this case study are described in the conclusion of the paper. 


\section{RELEVANT CHARACTERISTICS OF ACADEMIC RESEARCH}

\subsection{ACADEMIC RESEARCH CENTRE PIMES}

The innovation process described in the following chapter was applied to the research management of the academic research platform "PIMES - Process Improvement for Mechatronic and Embedded Systems" at Dortmund University of Applied Sciences and Arts, Germany. The focus of this research platform is to transfer scientific findings into industrial application by adapting and refining the scientific methodology and by testing and evaluating it in real world scenarios. This requires a strong collaboration with industry partners.

The research platform is focusing on engineering. It is run by 7 professors and employs $20+$ scientific staff members. Approximately $15+$ projects with funding volumes between $10.000-300.000$ EUR are executed in parallel. The research platform serves as an example for the case study evaluation.

\subsection{MAIN DRIVERS FOR A FUNDING PROJECT}

The main characteristics of the research management for the PIMES research platform are quite typical for academic research:

1. The researchers have a strong link into their scientific community and they are observing the relevant trends in their field of knowledge. From reading, discussing and reasoning about new trends, ideas for further research are generated.

2. To investigate such an idea, knowledge has to be acquired and competencies have to be developed. Research in a specific area has to be based on a strong scientific competence in this area and the right people in the research team.

3. Usually, partners are needed for cooperation. A project needs scientists as staff members. A consortium or a team has to be built and the researcher has to motivate the consortium to work on the topic.

4. To run a project on the research topic, funding has to be acquired. Academic research is at least partially dependent on public funding. Therefore, a funding application has to be written and to be addressed to the respective funding organizations. Since public funding is usually bound to certain research and innovation initiatives, it is necessary to meet the scope and requirements of a certain research programme.

From this brief summary of a typical way from an innovative idea to a research project the main inputs for a respective process can be derived. These inputs are the relevant scientific trends, the competencies and skills of the researchers, a consortium and a successful funding application within the scope of an open call for project proposals.

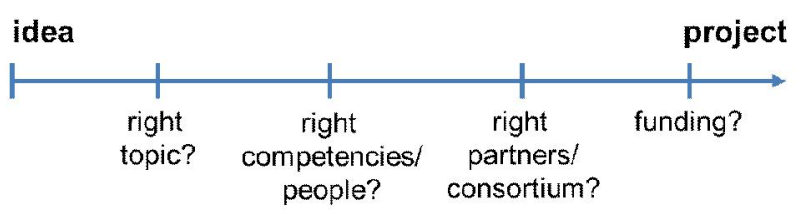

Fig. 1 - Typical Steps from an Idea to a Project.

\section{INNOVATION PROCESS AND TOOLS}

The following steps describe the process leading from a promising innovative idea to the start of a research project. In academia, this starting point of a project is usually a funding decision or a grant.

\subsection{IDEA2PROJECT PROCESS}

The idea2project process has the target to generate ideas from the analysis of trends and to refine and elaborate these ideas towards a research project.

\begin{tabular}{|l|ll|}
\hline Trends & $\begin{array}{l}\text { Trend } \\
\text { Radar }\end{array}>\begin{array}{c}\text { Innovation } \\
\text { Funnel }\end{array}$ & $\begin{array}{c}\text { Project } \\
\text { Pipeline }\end{array}$ \\
\hline
\end{tabular}

Fig. 2 - Simple Idea2Project Process.

The main steps are a trend analysis and a refinement of the project idea while processing it in an innovation funnel. The relevant tool for trend analysis is a Trend Radar [4]. If a trend becomes sufficiently relevant and mature for the academic research team, ideas for project proposals are generated. The next step is to feed new project proposals (or project ideas) into an innovation funnel [7]. After passing the innovation funnel, a project proposal is sufficiently elaborated and has received a funding approval. The project can be started and enters the project pipeline of the research team/platform. The whole process is aligned with the strategic goals of the research team (or the university) by applying an adapted balanced scorecard [5].

\subsection{TREND RADAR}

The trend radar or innovation radar is a tool that helps to define which areas have to be observed and at which stage a new trend or topic is close enough to the core of the research focus of the team (or to 
the middle of the radar screen) to be considered for a project proposal.

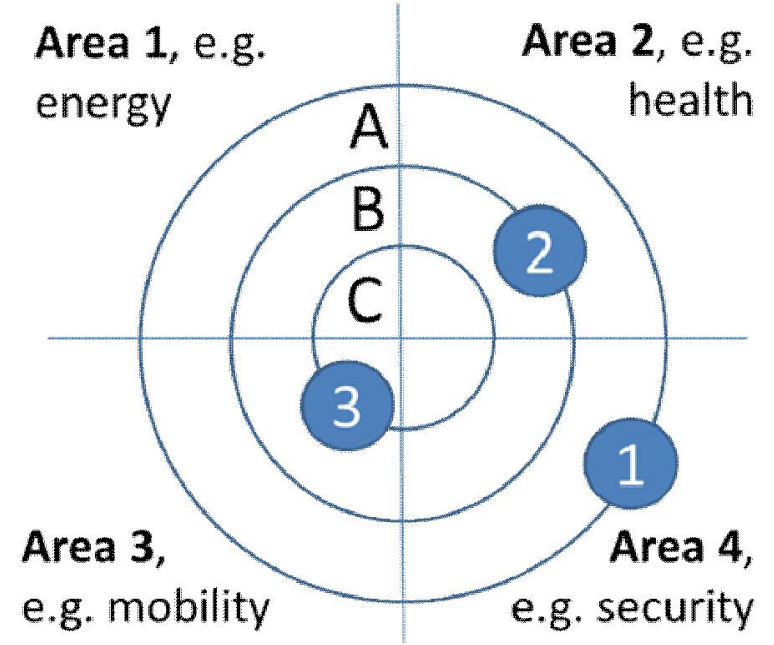

Fig. 3 - Trend Radar/Innovation Radar.

To set up the trend radar, the research team defines the relevant areas (e.g. Area 1: energy) it wants to observe. This can be derived from national or european technology roadmaps, the scientific profile of the research institution or just from the scope of the funding programs the team wants to target. If an interesting trend in one of the defined areas emerges, a respective dot (e.g. "1") on the radar screen is created outside of the outer ring. To move the dot closer to the middle, it has to pass a decision gate (e.g. to pass from ring A to ring B). At a decision gate, the trend is evaluated according to defined criteria (e.g. "is the trend mature enough for applied sciences?", "does the trend allow synergies with ongoing research projects?"). This evaluation can be done on a regular basis in team meetings. The relevance and maturity of a trend can be measured by objective criteria, e.g. the technology readiness level (TRL) [16]. If a trend reaches the middle of the radar, it is within the main scope of the research team. For such trends, project ideas may be created and evaluated.

\subsection{INNOVATION FUNNEL}

If a project idea fits to the scope of the research platform, the further elaboration is managed with an innovation funnel and a respective stage system.

Innovation funnels are widely used and adopted in innovation management, but their use can be contra-productive if done wrongly [9]. It is important to set the right scope for the use: The main goal of the innovation funnel is not to reduce the number of the ideas or to prevent ideas or project proposals to enter from outside. The main goal is to guide the researcher through the elaboration process and to provide milestones for this process [7]. Of course, new project proposals can enter the innovation funnel at any stage and therefore, the number of project proposals is not necessarily reduced from one stage to the other. Nevertheless, a structured process is provided. This is the basis for controlling and managing the idea2project process according to Fig. 2.

The main stages of the innovation funnel serve as decision gates and are defined as follows:

1. If an idea enters the funnel, a team with partners or a consortium has to be established. This step is completed, if a project outline has found a consensus amongst prospective consortium member and the decision to write a funding application is taken. The decision includes the setup of a timetable for writing the funding application and the assignment of tasks for the next steps.

2. In the next stage, resources need to be defined and competence has to be built up. This involves the analysis of the State-of-the-Art (SotA) to understand which competencies and resources are needed for the project. It has to be checked if the consortium can cover all required competencies or if other partners need to be added. This stage is concluded if a complete match between the consortium and the required competencies for the project is found.

3. A project description and a funding application need to be formulated. Funding has to be secured. At this stage, the funding application is discussed with public authorities and challenged according to the requirements of the respective funding call. It can be necessary to target a different call or to change and refine the proposal. After passing this stage successfully, the project can be started.

It is crucial to keep an overview and transparency over this process. This is required on project level for all partners. For the project portfolio of a research platform like PIMES, it is even more crucial to control the whole innovation funnel with all the project proposals inside. The target is to guarantee a constant flow of new funding into PIMES by generating a constant flow of successful funding proposals. Therefore, it is necessary to find a (graphical) representation showing at first sight the quantity of project porposals, the distribution over the different stages of the innovation funnel, the likelyhood of proceeding to a successful funding decision and the size of the prospective project (in terms of finance and resources).

In the example case shown in Fig. 4, colors are assigned to the projects in the funnel (e.g. "1" is green, "2" is yellow and "6" is red in Fig. 4) to show the current status. Green projects are on track, 
elaboration is ongoing but in time without major problems. Yellow projects are still in the funnel, but have some more or less severe issues or may be delayed. Red project proposals will not be elaborated any further and drop out of the funnel. With the graphical representation and the use of colors, the researchers can easily understand the loading and balancing within the funnel. If a stage shows too few project proposals or many red ones, the research team may run out of projects after some time. Mitigation measures have to be taken. In addition to the usage of colors, project importance or project size can be visualized by using a different size for the bubbles.

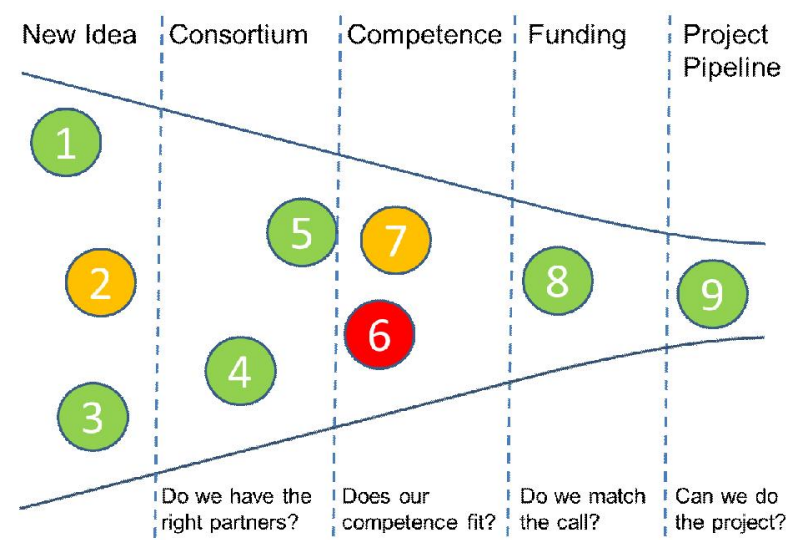

Fig. 4 - Innovation funnel.

For controlling the innovation funnel, key performance indicators (KPI) can be used. The intention is to get a quantitative measure for the effectiveness and efficiency of the innovation funnel. Basically, the target is to get an early warning if the innovation funnel does not generate the intended constant flow of projects. Fur this pupose, it makes sense to monitor the follwing data:

- Number of projects in each stage

- Drop out rate of project proposals at each stage

- Size of projects

- Likelyhood that project reaches next stage

- Degree of innovation (and risk) compared to previous projects

- Turn-around-time (TAT) for a project to move from one stage to the next one

The KPIs can be part of the balanced scorecard of the reasearch group. The criteria for balancing the innovation funnel can be part of the strategy map and the strategy development.

As a basis for the innovation funnel as a graphical representation, an innovation sheet can be used to give a textual description of the information gathered in the stages of the project proposal elaboration.
In the case of PIMES, the innovation sheet is used as kind of a $\log$ file documenting the development of an idea towards a project. Nevertheless, it contains all the information needed for generating the graphical representation of the innovation funnel and the KPIs for the scorecard. The innovation sheet is maintained in the Wiki of the collaboration tool of PIMES and can be edited by each researcher.

Table 1. Innovation Sheet Example.

\begin{tabular}{|c|c|c|}
\hline Stage & Date & Result \\
\hline New Idea & Jan 15,2012 & $\begin{array}{l}\text { AMALTHEA4public: } \\
\text { Open Source Tool Chain } \\
\text { for Automotive Software } \\
\text { Development }\end{array}$ \\
\hline \multirow[t]{5}{*}{ Consortium } & Feb 7, 2012 & $\begin{array}{l}\text { Discussion with the } \\
\text { German Sub Consortium } \\
\text { headed by Bosch. }\end{array}$ \\
\hline & Mar 5, 2012 & $\begin{array}{l}\text { Involvement of Finnish } \\
\text { Sub Consortium }\end{array}$ \\
\hline & Mar 20,2012 & $\begin{array}{l}\text { Presentation at ITEA PO } \\
\text { Days in Istanbul }\end{array}$ \\
\hline & April 2012 & $\begin{array}{l}\text { Expression of Interest by } \\
\text { Spanish and Turkish } \\
\text { Sub Consortia }\end{array}$ \\
\hline & April 2012 & Decision to go ahead \\
\hline Competence & May 2012 & $\begin{array}{l}\text { Adding Work Package } \\
\text { on Safety => Set up } \\
\text { Meeting with ifak } \\
\text { Institute to check } \\
\text { Requirements }\end{array}$ \\
\hline Funding & t.b.d. & \\
\hline Project Start & t.b.d. & \\
\hline
\end{tabular}

\subsection{MEETINGS AND COMMUNICATION}

The tools (trend radar, innovation funnel/innovation sheet, balanced scorecard) are used to visualize and document the process of moving from an idea to a project. Regular monthly meetings of the whole team are done to discuss the status of the trend radar and the innovation funnel and to take corrective actions. The researchers update the data in the innovation sheet if a project proposal was elaborated further. Information in the innovation sheet is accumulated and analyzed, reports are derived. Apart from the regular monthly meeting schedule, two strategic workshops per year are conducted. During these workshops, the balanced scorecard is updated or adapted and the scope of the trend radar is discussed. The tools help to structure the meetings and to give an easy and comprehensive overview to all team members. 


\subsection{CONFLUENCE}

The usage of the tools is supported by an IT system, the collaboration platform Confluence from Altassian [17]. The Confluence workspace of the research team contains the innovation sheet. Email notifications are generated if a team member updates the innovation sheet. The creation of the graphical representations and the report generation are partly automated. Key performance indicators for the balanced scorecard are stored and published within Confluence, too. They are part of the regular reporting towards the university board.

It is important to have a staff member who is maintaining the content and who is supporting and training the researchers in using the tools. The role is quite similar to a technology steward [14]. The technology stewart is preparing the reports and the KPIs for the monthly meetings and the balanced scorecard for the 2-day workshops. He is consulting and guiding the researchers thorugh the process. He is maintaining the data and cleaning up from time to time (e.g. taking out project proposals that dropped out of the innovation funnel). Furthermore, this person is facilitating the meetings and taking the notes and action items. Meeting notes and action item lists are supported by Confluence, too. The generation of issue tickets and the issue tracking are additional features. Data can be developed and maintained easily within Wikis. By providing web access and email notifications, the whole idea2project process is transparent to all researchers.

\section{CONTROLLING THE IDEA2PROJECT PROCESS WITH THE BALANCED SCORECARD}

The innovation process has to be aligned with the strategic goals of the research team (or research platform). A typical tool for strategy development, strategy description and strategy controlling is the balanced scorecard [5]. The intention of the scorecard is to show the strategic levers and the influence of certain measures and results on these levers. Therefore, the main benefit of a balanced scorecard is strategy communication and clarification. Different dimensions are used to create a balanced view.

For the example case PIMES, the dimensions are adapted to academic research. For PIMES, the target is to combine the transfer of novel scientific finding into application with teaching and cooperation projects with industry and academia. Therefore, strategic elements for this scorecard are the sectors:

1. Applied/Industrial Research: This contains the targets and measures for cooperation and transfer projects with industrial partners. To succeed in this sector, PIMES has to have a good knowledge of the respective application domain and a professional, results-oriented working style. It is important to involve industry partners in teaching and to transfer PIMES alumni into industry jobs successfully. In general, the industry partners are a kind of customer for the PIMES results and for the students educated within PIMES. It is important to understand the different levers for generating a win-win situation between PIMES and the industry partners.

2. Academic Research: This is the main source of new scientific findings for PIMES. Bridging the gap between academia and industry is a key strength of PIMES. Therefore, it is very important to have a solid footprint in academic research. Furthermore, this footprint generates the basis for the Master and $\mathrm{PhD}$ education carried out within PIMES. By providing the knowledge about several application domains and excellent industry contacts, PIMES is an attractive partner in academic research.

3. Teaching: For a German University of Applied Sciences, teaching is the core business. The connection between teaching and research is mainly happening within the Master's programmes. Master students and $\mathrm{PhD}$ students are the core staff for the research projects. Results from the projects are transferred into teaching. PIMES is strongly involved in shaping content for Master programmes and in supervising Master theses and $\mathrm{PhD}$ theses.

4. Reputation: Building a reputation is important for the three previous sectors. It is necessary to attract industry and academic partners and to get the best students and staff on board. Reputation is built by publishing relevant results and by conducting interesting projects. Furthermore, at a University of Applied Sciences, reputation amongst students is generated by excellent teaching.

The strategic vision of the research platform (e.g. "we want to establish a competent research institution for mechatronics and embedded systems") is divided into goals within these four sectors (e.g. "we want to be acknowledged by the research community as an important partner in questions regarding technical process improvement" for the dimension "Academic Research").The views or perspectives of the scorecard are:

Learning \& Growth: This view contains the levers and goals for building up and maintaining the competence to succeed in the respective sector. In can include goals for conducting certain types of projects, training people, or getting a part time lecturer from industry. 
Customers/Partners: PIMES defines goals and mechanisms for getting the right people, partners and networks in this part. In case of industry and academia, this is clearly about research consortia. In the "Teaching" section, it is about getting the right students and lecturers.

Internal Processes:This perspective deals with the quality of the internal execution processes, e.g. if projects are executed on time and on budget and if they achieve the expected results. Actually, effective internal processes are a key for the success in building up competence and in satisfying the needs of partners and customers. The processes need to be standardized to some extent to guarantee a constant quality and they need to be automated to be efficient.

Finance: Finances in terms of funding are a source for the success in the other topics and at the same time they are a result of success and a quantifiable key performance indicator. Therefore, they are a very natural part of a balanced scorecard.

Table 2. Example of a Balanced Scorecard for PIMES with KPIs for the Strategic Levers.

\begin{tabular}{|c|c|c|c|c|}
\hline $\begin{array}{l}\text { Sector/ } \\
\text { Perspective }\end{array}$ & $\begin{array}{l}\text { Academic } \\
\text { Research }\end{array}$ & $\begin{array}{l}\text { Applied/ } \\
\text { Industrial } \\
\text { Research }\end{array}$ & Teaching & Reputation \\
\hline $\begin{array}{l}\text { Learning/ } \\
\text { Growth/ } \\
\text { Competence }\end{array}$ & $\begin{array}{l}\text { \# of } \\
\text { Competence } \\
\text { Areas }\end{array}$ & $\begin{array}{l}\text { \#+ Size of } \\
\text { Transfer } \\
\text { Projects }\end{array}$ & $\begin{array}{l}\text { \# of Master } \\
\& \mathrm{PhD} \\
\text { Theses }\end{array}$ & $\begin{array}{l}\#+ \\
\text { Quality of } \\
\text { Publications, } \\
\text { Demon- } \\
\text { strators }\end{array}$ \\
\hline $\begin{array}{l}\text { Partnersl } \\
\text { Customers }\end{array}$ & $\begin{array}{l}\text { \# of } \\
\text { University } \\
\text { Partners }\end{array}$ & $\begin{array}{l}\text { \# of } \\
\text { Industry } \\
\text { Partners }\end{array}$ & $\begin{array}{l}\text { \# Master } \\
\text { Students }\end{array}$ & $\begin{array}{l}\text { \# Reviews, } \\
\text { Committees }\end{array}$ \\
\hline $\begin{array}{l}\text { Internal } \\
\text { Processes }\end{array}$ & $\begin{array}{l}\text { Project } \\
\text { Execution } \\
\text { Excellence }\end{array}$ & $\begin{array}{l}\# \\
\text { Placements } \\
\text { of Alumni }\end{array}$ & $\begin{array}{l}\text { \# Summer } \\
\text { Schools }\end{array}$ & $\begin{array}{l}\text { Annual } \\
\text { Report, own } \\
\text { Conference }\end{array}$ \\
\hline Finance & $\begin{array}{l}\text { Public } \\
\text { Funding }\end{array}$ & $\begin{array}{l}\text { Industry } \\
\text { Funding }\end{array}$ & $\begin{array}{l}\text { Tuition } \\
\text { Fees, } \\
\text { Certificates }\end{array}$ & Rewards \\
\hline
\end{tabular}

As part of the strategy development according to the balanced scorecard process, the cause and effect chains for achieving the strategic targets are identified. This is done by connecting the strategic levers named in the relevant perspectives for the sectors/sub-targets with each other.

An example for a strategic lever within the sector "Teaching" and the perspective/view "Learning \& Growth" is the goal "Conduct cooperative PhDs with Universities". German Universities of Applied Sciences do not grant PhDs. Nevertheless, PhD students are very important for research. They guarantee a sustainable development of scientific competence areas. Therefore, the PIMES research platform defines annual quantitative targets for the number of PhD students. PhD students are medium term ( $\sim 5$ years) employees within PIMES and they are a major lever to build up competence. It is a common approach to put 2-3 PhD students on a new competence area and develop this with their research work. This competence area and their finding can lead to a successful funding application and of course their work leads to a closer cooperation with the university granting the $\mathrm{PhD}$ degree. Furthermore, their works leads to publications. Nevertheless, PIMES cannot employ $\mathrm{PhD}$ students without having funding projects and it cannot cooperate with universities without having a certain reputation due to relevant publications. Therefore, having funding and publications is a cause for getting $\mathrm{PhD}$ students. Funding is a direct cause. Publications are an indirect cause having effect via reputation and university cooperation.

Table 3. Example of a Strategy Map behind the Balanced Scorecard.

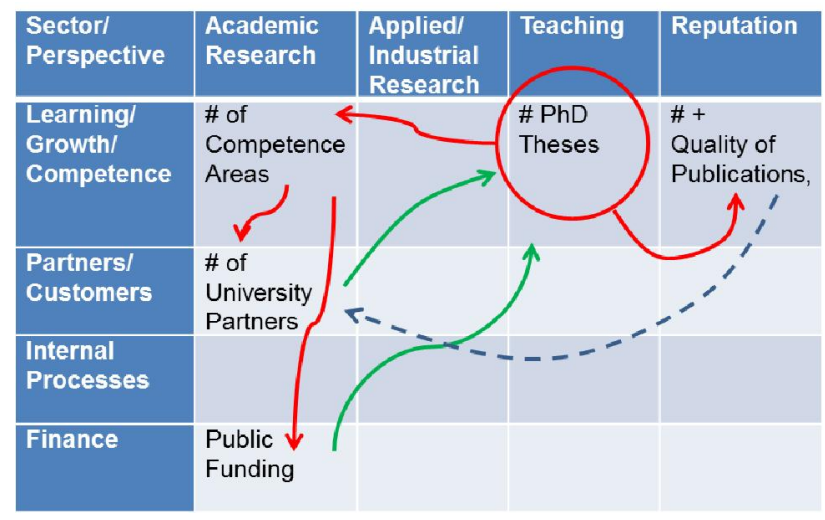

The scorecard for the PIMES example case contains around 15 measures/levers with respective quantitative goals and key performance indicators.

\section{EVALUATION IN A CASE STUDY}

The innovation management process idea2project is used within PIMES since approximately 4 years. There was a learning curve of about 1.5 years until the researchers really used the innovation sheet. Today the innovation sheet contains around 20 project proposals in all stages. Around 15 projects are in the project execution pipeline. Calls for project proposals are regularly reviewed and project proposals are generated according to the ideas. The graphical representation of the innovation funnel is used to keep an overview while discussing the innovation sheet during the monthly meetings.

The use of the trend radar is less established. The definition of the trends for observation is working quite well. It is fed by learning from previous projects, discussions with colleagues and industry partners and from analyzing the relevant technology roadmaps. Nevertheless, the decision if a trend moves to the middle of the radar is pretty much dependent on the expected benefit from the respective project idea in mind. Therefore, choosing 
trends is not fully driven by a real demand and a real match with the scope of the research platform but sometimes driven by opportunistic reasons.

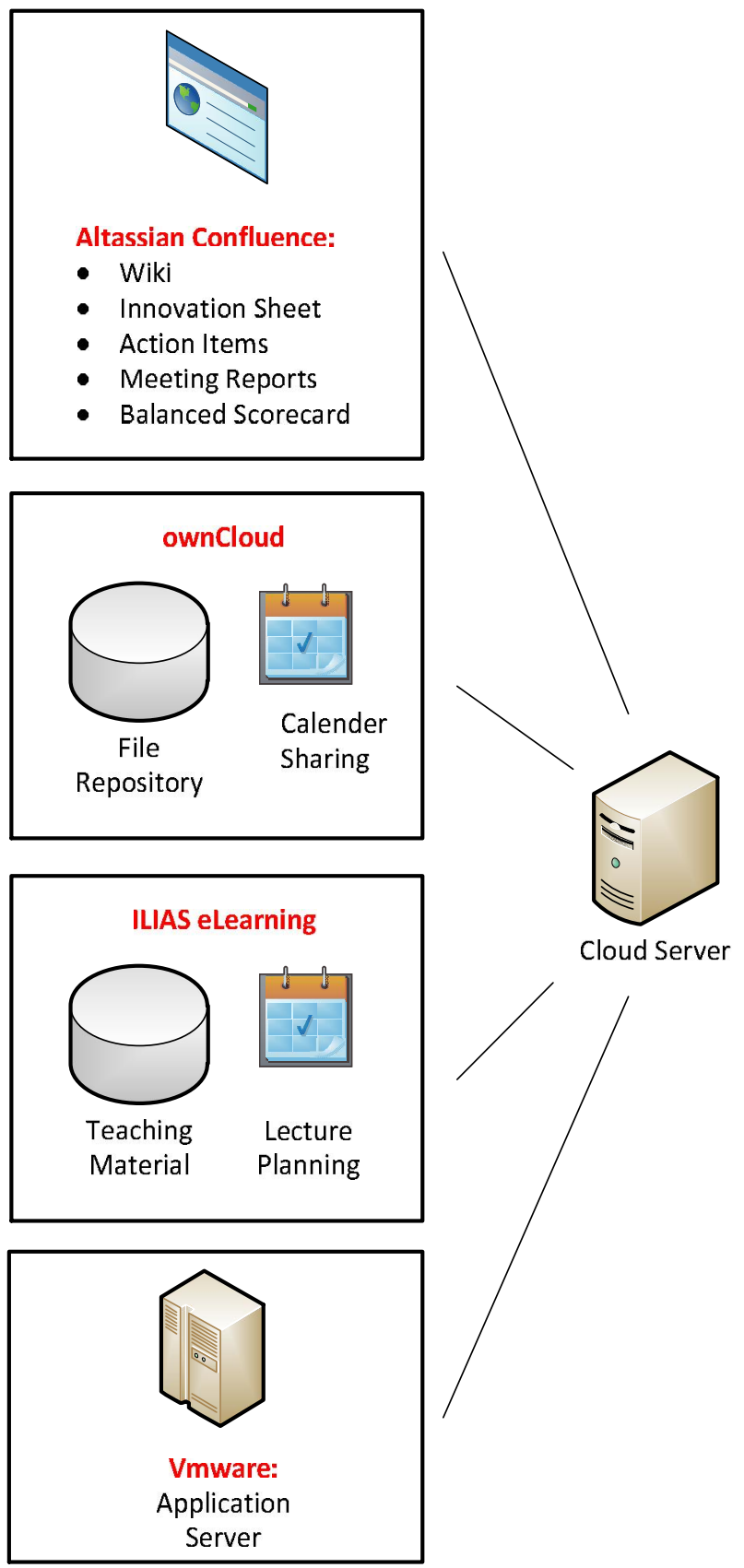

Fig. 5 - IT setup for PIMES example case.

Using a collaboration platform like Confluence makes it much easier to maintain the idea2project process and to make it transparent to all researchers. Information is stored centrally and compiled into reports and graphical representations for getting a fast and comprehensive overview. Apart from Confluence, PIMES uses ownCloud [18] as a file repository. For the teaching offers, the eLearning Management System ILIAS is used [19]. An application server (based on VMware, same as the other applications, too) completes the IT infrastructure of PIMES. The whole environment is operated on a multiprocessor server machine with RAID redundancy, automatic backup and fast internet connection. As said, operating the IT system and the tools requires specialist staff. The staff serves as technology steward for the researchers and as operator and maintainer of the systems.

The balanced scorecard is perceived as a valid instrument to keep all the goals of the research platform in mind and to understand the connection and causality of the goals. Furthermore, it is a very good tool for reporting key performance indicators. These key performance indicators are very useful to justify the work of the research platform in discussions with all the different stakeholders inside and outside of the university. Furthermore, it helps in evaluations and reviews of the work of the research platform and it can be used for target setting.

Overall, the process and the tools helped to structure an important part of the work of the research platform and to make academic research more professional. According to the researcher's individual perception, the results of the research platform became better in terms of quality and quantity, too. Nevertheless, this perception is not yet proven by comparison with research teams who do not use such processes and tools. An important comment from the researchers after a number of workshops is the finding that the tools helped to form a consensus about the research areas and the future direction of the research team. Furthermore, it helped to understand which parts each researcher can contribute to the goals.

\section{CONCLUSION}

By introducing a process and tools for the core business of an academic research platform - the generation of project proposals and the acquisition of funding - it is shown, that this highly creative and intuitive work can be supported and structured. The tools help to keep an overview about what future projects are in the funnel and what can be expected to be put into the project execution pipeline. The connection between trend radar and innovation funnel is straightforward. The measurement of the process performance and the alignment with the strategy by using a balanced scorecard adds the means to come to a comprehensive framework for managing academic research.

The further enhancement of the process, tools and IT systems includes setting up a professional risk management for PIMES, for the ongoing projects and for the innovation funnel. Financial management and controlling is another weakness which is typical for academic institutions. Apart 
from this, PIMES is working on project execution excellence, meaning a professional execution of research projects on time, on budget and with excellent results.

Further research is aiming to quantify the effects of the measures described. This can be done by comparison with similar research platforms that do not use these tools and processes. Nevertheless, getting such data will be tough since the performance of research platforms is difficult to measure and even more difficult to compare. Furthermore, research platforms are not really keen on serving as a bad example in a benchmarking.

\section{REFERENCES}

[1] H. Chesbrough, Open Innovation: The New Imperative for Creating and Profiting from Technology, Harvard Business School Press, 2003.

[2] P. Clancy, D. D. Dill (eds.), The Research Mission of the University Policy Reforms and Institutional Response, Issues in Higher Education, Rotterdam, The Netherlands, Sense Publishers, 2009, pp. 3-17.

[3] D. D. Dill, M. Beerkens, Designing the framework conditions for assuring academic standards: lessons learned about professional, market, and government regulation of academic quality, Higher Education, Springer, 2012, pp. 1-17.

[4] M. Durst, F. Greif, L. Stoesser, F. Edelmann, Collaborative trend management, in Proceedings of the XXII ISPIM Conference, Hamburg, 2011, pp. 1-13.

[5] R. S. Kaplan, D. P. Norton, The balanced scorecard - measures that drive performance, Harvard Business Review, January-February, 1992, pp. 71-79.

[6] H. Kerzner, Project Management: A Systems Approach to Planning, Scheduling, and Controlling, $8^{\text {th }}$ edition, Wiley, 2003.

[7] S. Kyffin, P. Gardien, Navigating the innovation matrix: An approach to design-led innovation, International Journal of Design, (3) 1 (2009), pp. 57-69.

[8] V. Lynn Meek, Market coordination, research management and the future of higher education in the post-industrial era, UNESCO Forum Occasional Paper Series, Paper No. 5, 2003, pp. 1-30.

[9] D. Nichols, Why innovation funnels don't work and why rockets do, Market Leader, Issue 38, Autumn 2007, pp. 26-31.
[10] L. C. Powers, G. Kerr, Project management and success in academic research, RealWorld Systems Research Series, (2) (2009), pp. 1-11.

[11] N. D. D. Preezl, L. Louw, A framework for managing the innovation process, in Proceedings of the Portland International Conference on Management of Engineering Technology (PICMET'08), 2008.

[12] F. Schuetzenmeister, University Research Management: An Exploratory Literature Review, eScholarship, University of California, Berkeley, 2010, pp. 1-32.

[13] M. Soo, The facts and fads in academic research management, OECD/IMHE Conference, 13-15 September 2010.

[14] E. Wenger, N. White, J. D. Smith, Digital Habitats. Stewarding Technology for Communities, CPSquare, United States, USA, 2010.

[15] C. Wolff, B. Igel, U. Lauschner, Innovation management processes for academic research, in Proceedings of the $7^{\text {th }}$ IEEE International Conference on Intelligent Data Acquisition and Advanced Computing Systems: Technology and Applications, Berlin, Germany, (12-14 September 2013), pp. 526-529.

[16] European Union: Horizon 2020 - Work programme 2014-2015, Annex G: Technology readiness levels (TRL).

[17] Altassian Confluence: https://www.atlassian. $\mathrm{com} /$ software/confluence

[18] ownCloud: http://owncloud.org/

[19] ILIAS: http://www.ilias.de

[20] PIMES: www.pimes.de

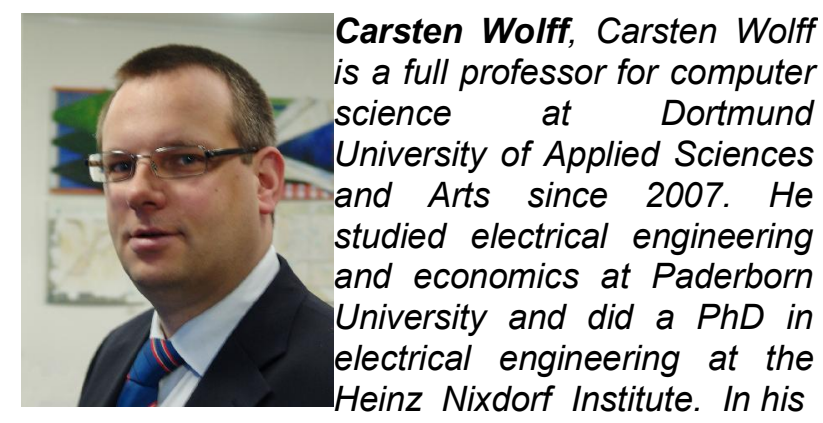
industrial career, Dr. Wolff was in the semiconductor industry (Infineon AG). He is a founding member of the research centre PIMES (www.pimes.de). His main research interests include development methodology and tools for embedded systems, processor technology, and transfer projects in the field of mechatronic systems, mobile communications, and renewable energy. 


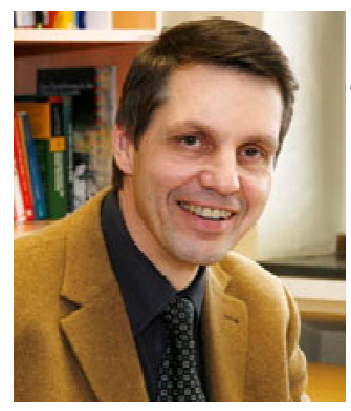

Burkhard lgel, is a full professor for software and control engineering at Dortmund University of Applied Sciences and Arts since 1995. He studied electrical engineering and computer science and did a Ph.D. in computer science. In his industrial career, Dr. Igel was

with Siemens AG. He is a founding member of the research centre PIMES (www.pimes.de). His main research interests include Model Driven Software Development, Software interaction of embedded systems and HMI and applications in the field of mechatronic systems.

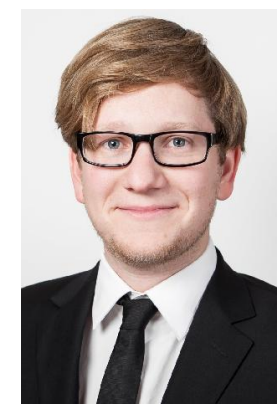

Uwe Lauschner, is a PhD student at Dortmund University of Applied Sciences and Arts in cooperation with Bielefeld University. He completed his studies in information and communication technology at Dortmund University of Applied Sciences and Arts in 2014. Mr. Lauschner is employed at the research centre PIMES (www.pimes. de) and conducts research model based development in the field of robotics. 